\title{
Experimental Antiviral Therapeutic Studies for Human Rhinovirus Infections
}

\author{
James A Coultas (D) \\ John Cafferkey $\mathbb{D D}^{2}$ \\ Patrick Mallia $\mathbb{D}^{\prime}$ \\ Sebastian L Johnston (D)' \\ 'National Heart and Lung Institute, \\ Imperial College London, London, UK; \\ ${ }^{2}$ Respiratory Medicine, St Mary's \\ Hospital, Imperial College Healthcare \\ Foundation Trust, London, UK
}

\begin{abstract}
Rhinovirus infection is common and usually causes mild, self-limiting upper respiratory tract symptoms. Rhinoviruses can cause exacerbation of chronic respiratory diseases, such as asthma or chronic obstructive pulmonary disease, leading to a significant burden of morbidity and mortality. There has been a great deal of progress in efforts to understand the immunological basis of rhinovirus infection. However, despite a number of in vitro and in vivo attempts, there have been no effective treatments developed. This review article summarises the up to date virological and immunological understanding of these infections. We discuss the challenges researchers face, and key solutions, in their work to investigate potential therapies including in vivo rhinovirus challenge studies. Finally, we explore past and present experimental therapeutic strategies employed in the treatment of rhinovirus infections and highlight promising areas of future work.
\end{abstract}

Keywords: antiviral agents, respiratory tract infections, rhinovirus, therapeutics

\section{Introduction}

Rhinoviruses (RVs) are among the most abundant of the respiratory viruses known to man. They predominantly cause mild self-limiting illness in healthy individuals but they are associated with significant morbidity in those with chronic lung disease. RVs were first identified in 1956 by WH Price at Johns Hopkins university during a search for the aetiology of the common cold, ${ }^{1}$ but have since been implicated as one of the main causes of both asthma ${ }^{2}$ and chronic obstructive pulmonary disease (COPD) exacerbations. ${ }^{3}$ RVs have also been implicated in lower respiratory tract infections (LRTIs), with one study showing RV-A and RV$\mathrm{C}$ present in around half of all cases of hospitalised LRTIs. ${ }^{4}$ During the SARSCoronavirus- 2 pandemic which resulted in numerous national lockdowns, the transmission of nearly all respiratory viruses was halted with the exception of RV. $^{5}$ There have been numerous attempts at producing an effective antirhinovirus therapy, but that goal remains unrealised. In this review, we discuss the structure of RVs, the immune response to infection, development of the human rhinovirus challenge model, and the historical as well as current state of antiviral research.

\section{Background Virology}

RVs are members of the Picornaviridae family and are located within the Enterovirus genus. ${ }^{6}$ Like other enteroviruses, RVs are single stranded and positive-sense viruses. ${ }^{7}$
Correspondence: James A Coultas
National Heart and Lung Institute, Imperial College London, Norfolk Place, London, W2 IPG, UK

Email james.coultas@nhs.net 


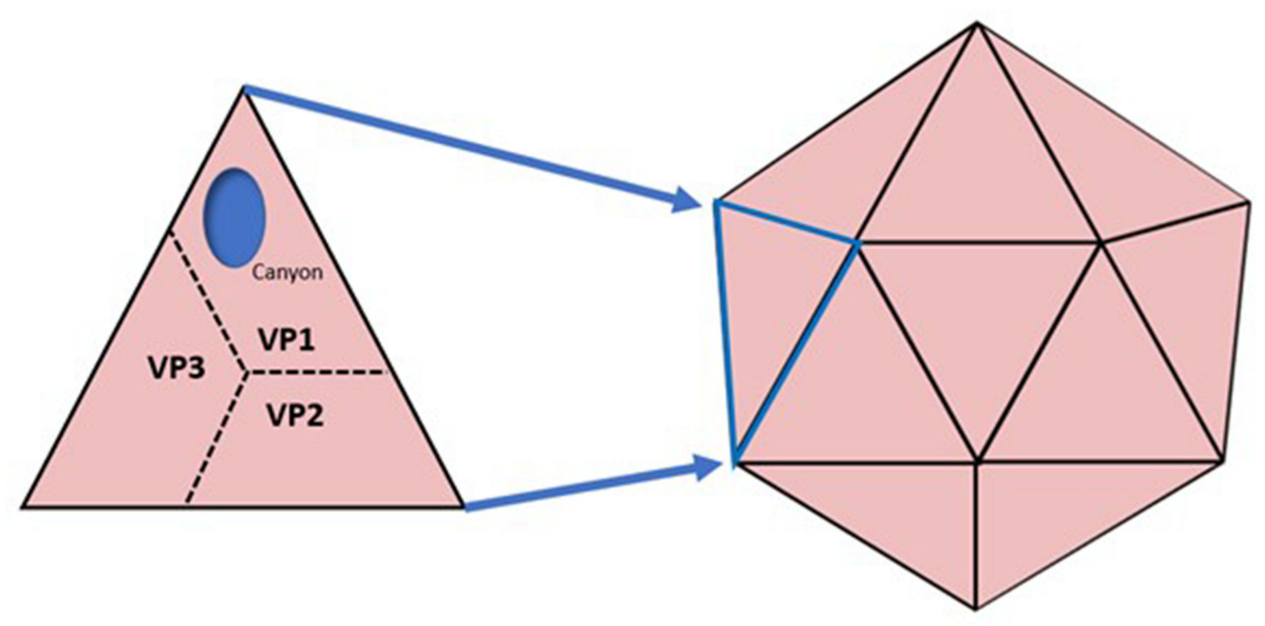

Figure I The icosahedron shape of the HRV viral capsid showing the orientation of the VP proteins.

RVs are currently classified into 3 species according to variations within their RNA genome. ${ }^{8}$ The RV-A species currently has 77 strains, whilst RV-B has 29 strains. $^{9}$ In 2006, a novel rhinovirus clade was identified in New York City and, aided by advances in genome sequencing, was found to represent a new genotype termed RV-C; ${ }^{10} \mathrm{RV}-\mathrm{C}$ currently contains 60 strains. ${ }^{11}$

The RV genome is particularly susceptible to random point mutations due to a lack of traditional RNA proofreading mechanisms. The result is an enormous amount of antigenic variation which allows individuals to have multiple seasonal RV infections despite each infection stimulating a memory immune response. The large antigenic diversity also provides a hurdle to vaccine and antiviral therapy creation and helps to explain why effective therapies remain elusive.

The RV genome encodes a single gene which is subsequently cleaved to create 11 individual proteins which provide the functions needed for the virus to survive, invade, and replicate. ${ }^{12}$ The genome can therefore be divided according to these processes. At the 5-prime end is an untranslated region (5'UTR), followed by the P1, P2, and P3 regions, before terminating with a 3'UTR and a poly-A tail. ${ }^{8}$ The $\mathrm{P} 1$ region encodes the structural viral proteins (VP) which form the protective viral capsid and are the main target of the host immune response. ${ }^{8}$ The P2 region performs roles in virus replication. The $\mathrm{P} 3$ region is predominantly involved in viral replication but also plays a role in modulation of the host immune response.

The P1 region is divided into sub-sections termed 1A1D which in turn encode the structural proteins VP4-VP1, respectively. The $\mathrm{P} 2$ region $(2 \mathrm{~A}-2 \mathrm{C})$ encodes a cysteine protease (protease $2 \mathrm{~A}$ ) which acts at the $\mathrm{P} 1-\mathrm{P} 2$ junction to cleave the $\mathrm{P} 1$ region from the rest of the translated viral polyprotein. ${ }^{8}$ Protein $2 \mathrm{~B}$ is a viroporin involved in virus efflux from an infected host cell and also assists in recruiting host cell protein machinery to aid viral replication. $2 \mathrm{C}$ binds intracellular host proteins but its exact role is not clear. The $\mathrm{P} 3$ region (3A-3D) begins with protein $3 \mathrm{~A}$, which interacts with the PI4KB protein and assists replication. ${ }^{13}$ The role of $3 \mathrm{~B}$ remains unclear but appears to also assist with viral replication. ${ }^{14}$ Protein $3 \mathrm{C}$ is another protease which cleaves and degrades the cytosolic pattern recognition receptor, retinoic acid-inducible gene I (RIG-I) which results in attenuated host type I interferon (IFN) production. ${ }^{15}$ The final protein of the $\mathrm{P} 3$ region is $3 \mathrm{D}^{\mathrm{pol}}$, an RNA-dependent RNA polymerase (RdRps) which synthesises new viral RNA during replication. ${ }^{16}$

The VP proteins of the P1 region form an icosahedron shape which becomes the viral capsid (Figure 1). Each triangular face of the icosahedron is formed of a single VP1, VP2 and VP3 on the surface, whilst the VP4 protein is hidden on the internal surface of each face. Within the VP1 protein is a hydrophobic depression, commonly termed a "canyon", which is important in virus-cell binding. ${ }^{17}$ The VP1 canyon is currently postulated to be the ligand for host cell intercellular adhesion molecule 1 (ICAM-1) ${ }^{18}$ In RV-C, the VP1 canyon is collapsed and contains hydrophobic residues (such as Trp1080, Phe 1096, and Met1116). ${ }^{19}$ Changes in the canyon here make RV-C less susceptible to drugs that target amino acids in this region.

Furthermore, RVs can be classified into major and minor groups based on which host cell receptor they 
bind to. Major group RVs bind to ICAM-1 and include most serotypes of HRV-A and HRV-B, whilst the minor group RVs bind to low-density lipoprotein receptor (LDLR). ${ }^{20} \mathrm{RV}-\mathrm{C}$ strains bind to cadherin-related family member 3 (CDHR3). $^{21,22}$

Understanding the fundamentals of RV virology is key when considering potential therapeutic strategies, but also goes some distance to accounting for the modest success we have had in their implementation.

\section{Immune Response to RVs}

RVs primarily infect humans via nasal epithelial cells and are spread through expulsion and inhalation of microdroplets containing the virus. Depending on the RV type, and therefore its target receptor, RVs bind ICAM-1, LDL$\mathrm{R}$, or CDHR3 expressed on nasal epithelium and macrophages. ${ }^{23} \mathrm{RVs}$ are engaged by various pattern recognition receptors (PRR), including Toll-like receptor 2 (TLR2) on the cell surface and intracellular TLR3, TLR7, and TLR8. ${ }^{7}$ Other intracellular PRRs that play a role include RIG-I and melanoma differentiationassociated protein 5 (MDA-5) which are both cytosolic. Whilst different receptor groups use separate cellularsignalling pathways, they all result in the transcription and production of type I IFNs (IFN- $\alpha$, IFN- $\beta$ ) and type III IFNs (IFN- $\lambda 1$, IFN- $\lambda 2$, IFN- $\lambda 3$ ). ${ }^{24}$ IFNs appear to be crucial to the early anti-RV immune response and have several roles. IFNs induce Th1 antiviral adaptive responses, but also induce apoptosis of RV-infected cells, inhibit viral transcription and virus entry into cells. ${ }^{25}$ The inflammatory response is characterised by expression of cytokines (IL-1 $\beta$, IL-6, IL-11, TNF), chemokines (CXCL8, MCP-1, IP-10, RANTES) and various reactive oxygen species and vasoactive peptides. ${ }^{8,26,27}$ This inflammatory milieu contributes to the typical symptoms seen in the common cold of nasal congestion, discharge and sore throat in healthy individuals.

COPD patients are known to have impaired antiviral responses, as demonstrated through the rhinovirus infection model. ${ }^{28,29}$ Individuals are infected with the same quantity and serotype of RV at a controlled time point, allowing differences in the immune response to infection to be compared between COPD patients and healthy controls. Such models show that COPD patients have higher post inoculation viral loads and have exaggerated immune responses, with increased levels of cytokines (IL-1 $\beta$, IL-6, TNF, CXCL8), neutrophil elastase, matrix metalloprotease-9 (MMP-9) and oxidative stress. ${ }^{29,30}$ Cells sampled by bronchoalveolar lavage from COPD patients post RV challenge showed deficient IFN production. ${ }^{29}$ The increased virus loads observed, as well as the consequent increased inflammatory responses, likely result from deficient IFN responses to infection in COPD. ${ }^{29,31,32}$ Wark et al demonstrated that $\mathrm{pBEC}$ from COPD patients had impaired IFN responses when pre-treated with exogenous IFN- $\beta .^{33}$ A subset of COPD patients with frequent exacerbations has been identified as a potential target group for IFN therapies. ${ }^{34}$

Asthma patients also have impaired antiviral immune responses. A landmark 2005 study was the first to show impaired control of RV replication within primary human bronchial epithelial cells (HBECs) from people with asthma. $^{35}$ Further studies have confirmed both deficient IFN- $\beta$ and IFN- $\lambda$ responses in people with asthma. ${ }^{36,37}$ In vivo studies have found increased concentrations of IFNs during RV induced asthma exacerbations, ${ }^{38,39}$ likely a result of increased virus loads consequent upon deficient early IFN responses. Work by Kennedy et al found no difference in viral loads in small numbers of subjects (16 with asthma, 8 without) who participated in an experimental challenge with $\mathrm{RV},{ }^{40}$ while a study of larger numbers (28 with asthma and 11 without) found nasal virus load was increased $\sim 250$-fold on day 3 . RV infection in asthma also stimulates the airway epithelium to produce the cytokines IL-25, IL-33 and thymic stromal lymphopoietin (TSLP) that activate type 2 innate lymphoid cells (ILC2s) and T helper 2 (Th2) cells. ${ }^{41,42}$ RV infection in asthma therefore induces a type 2 response typical of asthma exacerbations.

\section{Experimental RV Infection Model History of the Model}

The virus challenge model in humans, also known as experimental infection, has been used to better understand the immune response to RV infection and also the efficacy of various therapeutics. The study of most infections relies upon experimental infection in animal models and natural infection in humans.

Studying natural infections is problematic in the case of $\mathrm{RV}$ for a number of reasons: infected individuals are frequently asymptomatic early in the course of infection the most plausible time that intervention will be effective; infections are usually mild and self-limiting, requiring sensitive and early reporting on the part of patients in order to be identified; and there are other respiratory 
viruses clinically indistinguishable from RV infection, so natural infection studies would require large numbers of participants over a long time course in order to sufficiently power analysis. The mild and self-limiting nature of RV infection means that illness is almost always tolerable, safe and temporary in healthy adults. This has allowed pioneering researchers to develop methods of causing RV infections in humans in a predictable manner allowing the study of illness and assessment of therapies.

Initial attempts can be traced back to the Medical Research Council's Common Cold Research Unit in Salisbury, where individuals were isolated in small groups for 'holidays' in order to study viral transmission and work focused on the attempt to isolate and propagate virus in culture. ${ }^{43,44}$ Here, virus inoculation in healthy volunteers was attempted with nasal drippings from symptomatic individuals, with a success rate of $60 \%{ }^{45}$ These efforts paved the way for subsequent efforts in centres in Chicago, Bethesda, Baltimore and Charlottesville, the latter focusing specifically on RV and intranasal IFNs. ${ }^{43}$ Advances in laboratory culture and genetic identification of virus species progressed gradually until the advent of highly sensitive molecular identification techniques including PCR, notably allowing the detection and classification of the RV-C species. ${ }^{8}$

A large number of different strains have been used in experimental infection models to date, primarily from group A RVs: RV- $1,{ }^{46} \mathrm{RV}-2,{ }^{47} \mathrm{RV}-9,{ }^{48} \mathrm{RV}-16,{ }^{49-53} \mathrm{RV}-$ $24,{ }^{54} \mathrm{RV}-23,{ }^{55} \mathrm{RV}-29,{ }^{56} \mathrm{RV}-32,{ }^{47} \mathrm{RV}-39,{ }^{57} \mathrm{RV}-44,{ }^{47,58}$ and Hank's strain. ${ }^{59}$ RV-14, a group B rhinovirus has also been used in a single experimental infection ${ }^{60}$ (Table 1). No experimental inoculation has occurred with group C RVs to our knowledge.

Whilst many of these RV strains have been well established, cultured and tested to a very high standard and have a track record of safety in clinical trials, most have been developed outside of a formal regulatory framework. This is because the developments occurred at a pace which outstripped that of regulators. In the UK, the Academy of Medical Sciences have published a report which suggests that explicit guidance on the development of controlled human infection models is warranted. ${ }^{62}$

\section{Findings of Experimental RV Models}

The human RV challenge model has allowed both validation of in vitro findings and a comprehensive (and clinically relevant) understanding of symptoms, signs and sequelae of RV infection. The same dawn of molecular mechanisms which identified the breadth of RV species also revealed their importance in chronic lung conditions. In asthma exacerbations two thirds of viral infections, by far the most common cause of exacerbation, are RV species. ${ }^{63}$ Experimental RV infection in asthma has facilitated the elucidation of inflammatory processes and identified therapeutic targets for therapies in both acute and chronic management of the disease.

Our understanding of COPD exacerbation has similarly progressed with the use of RV models. Viral infections are far more common an aetiology than bacterial infections ${ }^{7}$ and experimental RV infection allows controlled exacerbation which similarly allows for a comprehensive understanding of immune response, identification of therapeutic strategies and evaluation of treatments in a more effective way than natural infection studies. ${ }^{29}$

RV challenge has become the critical first step for Phase II trials for not just anti-RV therapies but also drug whose aim is to reduction in burden of asthma and COPD exacerbation. Despite the human challenge model presenting a significant improvement in the drug discovery process, and a number of potential treatments being tested with this method, none have been successfully licensed for use in the treatment of RV infection to date. ${ }^{64}$

\section{Antiviral Therapies}

Table 2 summarises the actions and evidence of antiviral therapies discussed in this section.

\section{Ribavirin}

Ribavirin has a broad spectrum of activity and has been used to treat respiratory syncytial virus (RSV), Lassa fever, influenza and hepatitis $\mathrm{C}$ (in combination with pegylated IFN- $\alpha$ ). ${ }^{73}$ It is a synthetic nucleoside (a guanine analogue which acts by inhibiting inosine monophosphate dehydrogenase) and has a range of antiviral properties both direct (impairing viral mRNA synthesis and increasing viral mutation rates) and indirect (including upregulation of the host immune response). ${ }^{77}$ It has been long established that ribavirin is effective in vitro against a number of RV strains, especially when used prophylactically. ${ }^{71,72}$

However, the only in vivo evidence has been in a case series treating persisting lower respiratory tract symptoms caused by recurrent RV infection in four patients with hypogammaglobulinaemia. Oral ribavirin was administered with pegylated IFN- $\alpha 2 \alpha$, and was associated with a marked decrease and clearance of RV RNA. However, 
Table I RV Strains Used in Human Experimental Infection Models

\begin{tabular}{|c|c|c|}
\hline $\begin{array}{l}\text { RV } \\
\text { Group }\end{array}$ & Strain & Use Examples \\
\hline \multirow[t]{9}{*}{ A } & $\mathrm{RV}-2$ & $\begin{array}{l}\text { A double-blind placebo controlled trial of chalcone as prophylaxis against RV-2 infection demonstrated no evidence of } \\
\text { benefit. } 61\end{array}$ \\
\hline & RV-9 & $\begin{array}{l}\text { Three trials are reported assessing an experimental antiviral compound, } \mathrm{R} 6 \mid 837 \text {, acting on the virus capsid protein, } \\
\text { against RV-9 inoculation in volunteers. The compound demonstrated reduction in symptoms when used prophylactically } \\
\text { but not when commenced shortly after infection. }{ }^{48}\end{array}$ \\
\hline & RV- 16 & $\begin{array}{l}\text { This strain has been used widely in therapeutics trials but also notably was used in the development of an experimental } \\
\text { model of viral COPD exacerbation. }{ }^{28}\end{array}$ \\
\hline & RV-24 & $\begin{array}{l}\text { Used in early rhinovirus challenge trials, including a } 1973 \text { study assessing an antiviral compound, 3,4-dihydro- } \\
\text { I-isoquinolineacetamide hydrochloride, as prophylaxis against RV-24 inoculation. This placebo controlled study } \\
\text { demonstrated no benefit. }\end{array}$ \\
\hline & $\mathrm{RV}-23$ & $\begin{array}{l}\text { Echinacea or placebo was given to healthy volunteers } 14 \text { days prior to, and for } 5 \text { days after, inoculation with RV-23. No } \\
\text { significant difference in symptom scores or infections rates was detected. }{ }^{55}\end{array}$ \\
\hline & $\mathrm{RV}-29$ & $\begin{array}{l}\text { Intranasal administration, after inoculation of RV-29, of the antihistamine diphenhydramine hydrochloride was compared } \\
\text { against placebo in a double blind randomised controlled trial demonstrating a slight reduction in proportion of cold } \\
\text { symptoms. }{ }^{56}\end{array}$ \\
\hline & $R V-39$ & $\begin{array}{l}\text { The decongestant oxymetazoline was evaluated against placebo when administered soon after infection in a RV-39 } \\
\text { experimental model. Mean viral titre was reduced but viral shedding and clinical illness was not affected. }{ }^{57}\end{array}$ \\
\hline & $\mathrm{RV}-44$ & $\begin{array}{l}\text { An antiviral compound, "CL } 88,227 \text { ", or placebo, was given three times daily before and after RV-44 inoculation. It neither } \\
\text { prevented illness nor reduced symptom scores. } 58\end{array}$ \\
\hline & $\begin{array}{l}\text { Hank's } \\
\text { strain }\end{array}$ & $\begin{array}{l}\text { A three-armed randomised control trial compared oral pseudoephedrine with or without ibuprofen against placebo } \\
\text { following either experimental inoculation with Hank's strain or RV-39. Illness severity and rhinorrhoea was reduced in } \\
\text { treatment groups compared with placebo. }{ }^{59}\end{array}$ \\
\hline B & RV-I4 & $\begin{array}{l}\text { Volunteers were challenged with RV-9 and RV- } 14 \text { after prophylactic administration of intranasal recombinant human IFN- } \gamma \\
\text { or placebo, with no improvement in outcomes demonstrated. } .^{60}\end{array}$ \\
\hline
\end{tabular}

there was concomitant use of antibiotics, no clinical outcome data was provided, three of four experienced side effects and all patients had recurrent RV infection within months. ${ }^{73}$ It is also impossible to know whether the observed effect was due to ribavirin, IFN- $\alpha$, or a combined synergistic effect. The prospect of this formulation and dose of ribavirin seems limited even within confirmed, symptomatic and high-risk individuals.

\section{Capsid Binding Inhibitors Pleconaril}

Pleconaril is an orally absorbed low molecular weight compound which binds to the hydrophobic pocket of the $\beta$-barrell of the VP1 section of RVs, impairing viral capsid functions like attachment to cell receptors and viral RNA uncoating. ${ }^{78}$ Importantly, pleconaril has only weak activity against RV-C due to differences in the VP1 canyon and the amino acid sequences there. ${ }^{79}$ Two double blind randomised controlled trials have been conducted which evaluated participants experiencing symptoms from picornavirus infection as identified through real time PCR assays. Combined, 681 patients were randomised to pleconaril and 682 to placebo. Analysed individually, only one study met its primary end goal of reduction in time to alleviation of illness (defined by absent or mild cold symptoms in five domains for over 48 hours), although combined analysis suggested a statistically significant reduction overall (a median of 6.3 versus 7.3 days, $\mathrm{P}<0.001$ ). This effect did not reach statistical significance in all comers - ie, participants with no virus or nonpicornavirus isolated - and more side effects were experienced overall in the pleconaril arm. ${ }^{70}$

When submitted to the Food and Drug Administration (FDA) for approval in 2002 for the treatment of the common cold, it was declined as a number of other issues were identified with the results from the above studies and from 
Table 2 Summary of Mechanism and Evidence for Key Anti-RV Therapies

\begin{tabular}{|c|c|c|}
\hline Therapeutic & Proposed Mechanism of Action & Existing Evidence \\
\hline Azithromycin & Induction of IFN- $\beta$ and IFN- $\lambda$ in host response to RV & $\begin{array}{l}\text { Indirect evidence only via studies in asthma exacerbations, where } \\
\text { long term prophylaxis of } 420 \text { patients as part of a randomised } \\
\text { placebo-controlled trial reduced the number of exacerbations and } \\
\text { improved quality of life. }{ }^{65} \text { In a separate study in acute exacerbations, } \\
\text { no benefit was demonstrated. }\end{array}$ \\
\hline Budesonide & $\begin{array}{l}\text { Reduction in pro-inflammatory cytokines, protection of } \\
\text { host cells from cytotoxicity }\end{array}$ & No evidence from human clinical trials to date. \\
\hline Gemcitabine & Inhibition of viral proliferation and viral RNA synthesis & No evidence from human clinical trials to date. \\
\hline $\begin{array}{l}\text { Host defence } \\
\text { peptides }\end{array}$ & $\begin{array}{l}\text { Exogenous bolstering of the host innate immune } \\
\text { response }\end{array}$ & No evidence from human clinical trials to date. \\
\hline IFN- $\beta$ & $\begin{array}{l}\text { Exogenous correction of impaired IFN response in } \\
\text { asthma and COPD patients }\end{array}$ & $\begin{array}{l}\text { A randomised placebo-controlled trial of } 147 \text { people with asthma } \\
\text { tested inhaled IFN- } \beta \text { within } 24 \text { hours of a naturally occurring cold } \\
\text { symptoms. It failed to meet its primary endpoint, likely due to less } \\
\text { severe than expected exacerbations. }{ }^{67}\end{array}$ \\
\hline Itraconazole & Reduced viral replication and suppression of inflammation & No evidence from human clinical trials to date. \\
\hline Nitric oxide & $\begin{array}{l}\text { Direct inhibition of rhinovirus replication and inhibition } \\
\text { of pro-inflammatory cytokine production }\end{array}$ & No evidence from human clinical trials to date. \\
\hline Pirodavir & $\begin{array}{l}\text { Binding to viral capsid protein, inducing conformational } \\
\text { change and preventing adsorption and RNA uncoating }\end{array}$ & $\begin{array}{l}\text { I00 patients were enrolled across three randomised placebo- } \\
\text { controlled studies assessing pirodavir as prophylaxis against } \\
\text { experimental viral challenge of rhinovirus strains, and demonstrated } \\
\text { a reduction in symptoms. } 32 \text { patients enrolled in a randomised } \\
\text { placebo-controlled study treated after inoculation did not } \\
\text { demonstrate the same benefit. }{ }^{68} \mathrm{~A} \text { later randomised controlled trial } \\
\text { of } 98 \text { patients in the context of naturally occurring colds did not } \\
\text { demonstrate a clinical benefit. }{ }^{69}\end{array}$ \\
\hline Pleconaril & $\begin{array}{l}\text { Binding to and impairing critical viral capsid functions of } \\
\text { attachment and RNA uncoating }\end{array}$ & $\begin{array}{l}\text { Combined analysis of two randomised placebo-controlled trials in } \\
\text { a total of } 1363 \text { patients symptomatic with naturally occurring } \\
\text { picornavirus infections demonstrated a reduction in time to } \\
\text { alleviation of illness, although more side effects were experienced in } \\
\text { the active treatment arm. }{ }^{70}\end{array}$ \\
\hline Quercetin & Reduces RV replication and host cytokine response. & No evidence from human clinical trials to date. \\
\hline Ribavirin & $\begin{array}{l}\text { Direct: impairing viral RNA synthesis and increasing viral } \\
\text { mutation rates. Indirect: upregulation of host immune } \\
\text { response. }\end{array}$ & $\begin{array}{l}\text { Efficacy demonstrated prophylactically in vitro. }{ }^{71,72} \text { In vivo work is } \\
\text { limited to a case series of } 4 \text { patients with hypogammaglobulinaemia } \\
\text { where it was used in combination with IFN- } \alpha .^{73}\end{array}$ \\
\hline Rupintrivir & $\begin{array}{l}\text { Inhibits the } 3 C \text { protease by bonding to the active site on } \\
\text { the viral protease }\end{array}$ & No evidence from human clinical trials to date. \\
\hline Tremacamra & $\begin{array}{l}\text { Blocking viral entry and reduction in pro-inflammatory } \\
\text { cytokines }\end{array}$ & $\begin{array}{l}198 \text { adults were randomised across four trials to receive the } \\
\text { molecule in either pre- or post- experimental rhinovirus inoculation } \\
\text { studies. A reduction in symptom scores, clinical colds and } \\
\text { rhinorrhoea was demonstrated. }{ }^{74}\end{array}$ \\
\hline
\end{tabular}

(Continued) 
Table 2 (Continued).

\begin{tabular}{|l|l|l|}
\hline Therapeutic & Proposed Mechanism of Action & Existing Evidence \\
\hline Vapendavir & $\begin{array}{l}\text { Binding to viral capsid protein, inducing conformational } \\
\text { change and preventing adsorption and RNA uncoating }\end{array}$ & $\begin{array}{l}455 \text { asthmatic adults with naturally occurring (presumed) rhinovirus } \\
\text { infection in a randomised double-blind placebo-controlled trial } \\
\text { received vapendavir for } 6 \text { days after symptoms started. Although the } \\
\text { trial reported a significant reduction in cold symptoms at } 2 \text { to } 4 \text { days } \\
\text { post infection, the primary endpoint was not met. }\end{array}$ \\
\hline Vitamin D & $\begin{array}{l}\text { Supporting innate immune system via increased } \\
\text { cathelicidin and IFN stimulated genes }\end{array}$ & $\begin{array}{l}\text { A large recent meta-analysis of } 43 \text { trials and } 48,488 \text { participants } \\
\text { demonstrated that vitamin D supplementation reduces the incidence } \\
\text { of acute respiratory infections. }\end{array}$ \\
\hline
\end{tabular}

prior phase II trials, including concerns about interference with the action of oral contraceptives and the lack of a significant reduction in symptoms in non-white participants. Above all, the FDA thought that the requirement to take pleconaril within 24 hours of symptoms was unrealistic; an assessment that suggests a high threshold for licensing for any future RV treatment submissions. ${ }^{80}$

A further randomised, double blind, placebo controlled Phase II trial exploring intranasal pleconaril in asthma patients was completed in $2013 .{ }^{81}$ The study did not meet its primary endpoint of reducing asthma exacerbations.

\section{Pirodavir}

By 1991, several compounds had shown in vitro activity against either rhinovirus group A or group B. Pirodavir is a substituted phenoxy-pyridazinamine and was the first compound to show efficacy against both rhinovirus groups. ${ }^{82}$ Pirodavir binds to conserved amino acids in the hydrophobic canyon of the VP1 protein. Despite this not all strains of RV are susceptible to pirodavir. In particular, RV-8, RV-42, RV45 and RV-87 are resistant strains and this is believed to be due to different amino acid sequences in the canyon. After binding to the VP1 canyon, pirodavir mediates its effects by inducing a conformational change in the viral capsid protein which prevents adsorption and uncoating of the virus.

Pirodavir has undergone two clinical trials. This was first used as an experimental rhinovirus infection model where participants were directly infected with RV-39 or RV-Hanks and then allocated to a placebo or pirodavir group. ${ }^{68}$ Pirodavir was administered either prophylactically or 24 hours post infection. Significant reductions in viral shedding were seen in the pirodavir group regardless of the timing of administration. Reduction in common cold symptoms and clinical benefit however was only observed in the prophylactic group. This was replicated in a subsequent randomised double-blind placebo controlled trial of intranasal pirodavir which showed no clinical benefit of pirodavir against naturally occurring common colds, even though a reduction in viral shedding was observed. ${ }^{69}$

\section{Vapendavir}

Vapendavir is another capsid binder developed by Biota pharmaceuticals. A Phase IIb trial assessed response to natural upper respiratory tract infection (URTI) in 455 participants with moderate to severe asthma but did not meet its primary end point which was a reduction in symptoms (ACQ-6 questionnaire). ${ }^{83}$

\section{Novel Capsid-Binding Inhibitors}

One of the major drawbacks of capsid binding inhibitors like pleconaril and vapendavir is that they are ineffective against RVs with bulky hydrophobic VP1 canyons. These resistant RVs include RV-B5 and also the RV-C species, which account for a sizeable number of infections. New compounds have emerged that have broad canyon binding activity. OBR5-340 is a pyrazolopyrimidine that through in vitro work has shown to bind nearer to the entrance of the canyon compared to other capsid binders ${ }^{84}$ and demonstrate inhibition of resistant RV species. ${ }^{85}$ Another compound showing promising cross-species canyon binding is ca603 which has a similar structure to Pirodavir. In vitro work has shown that ca603 binds to pleconaril resistant RV species and inhibits viral replication through binding at the VP1 canyon site. ${ }^{86}$

\section{Novel RV Inhibitors}

\section{Rupintrivir}

Rupintrivir is another experimental anti-rhinovirus therapy that acts on the $3 \mathrm{C}$ protease. $\mathrm{RV}-3 \mathrm{C}$ protease inhibitors are 
based on a tripeptidyl structure and mediate their antiviral effects by forming a covalent bond with the active site cysteine amino acid on the viral protease. ${ }^{87}$ Dragovich et al showed that such antiviral effects could be further enhanced by adding a ketomethylene molecule to the tripeptidyl compound. ${ }^{87}$ This work led to the creation of rupintrivir (originally named AG7088).

Several in vitro studies have demonstrated the efficacy of rupintrivir against 48 serotypes of RV in HeLa cells, ${ }^{88,89}$ and in bronchial epithelial cells ${ }^{90}$ and such effects are mediated up to 26 hours after infection. In vivo studies of intranasally administered rupintrivir have shown a good safety profile $^{91}$ and moderate reduction in symptoms of a common cold and viral titres compared to a placebo. ${ }^{92}$ Due to limited clinical benefit, further trials of rupintrivir have not been undertaken. In more recent years, modification of rupintrivir with proline and azetidine molecules have shown in vitro anti-RV effects but are yet to be examined in vivo. ${ }^{93}$

Nitric oxide targeted approaches represent another strategy. Nitric oxide (NO) is produced by the respiratory epithelium as a physiological response to RV infection. NO is primarily synthesised by nitric oxide synthase (NOS) and its active metabolite S-nitroglutathione is conversely metabolised by $\mathrm{S}$-nitrosoglutathione reductase (GSNOR). NO has been shown to inhibit both rhinovirus replication and pro-inflammatory cytokine production. ${ }^{94}$ Yang et al have demonstrated that a specific GSNOR inhibitor, termed $\mathrm{C} 3 \mathrm{~m}$, reduced $\mathrm{RV}$ replication and also pro-inflammatory cytokines CXCL10, RANTES, and M. ${ }^{95}$ Interestingly, this appears to be due to its effects on ICAM-1 transcription as opposed to its GSNOR activity. NO-based therapies are currently in clinical trials for other respiratory viruses, notably SARS-CoV-2, and remain an unexplored avenue for treatment of RV.

Itraconazole has also exhibited anti-RV effects with reduced viral replication in infected mice lungs. There have currently been no clinical trials of itraconazole against $\mathrm{RV}{ }^{96}$

\section{Host Defence Peptides}

Host defence peptides (HDP) are proteins with antimicrobial properties and represent another arm of the innate immune system. They are secreted by leukocytes and epithelial cells, and principally fall into two groups: cathelicidins and defensins. The antiviral mechanism of human cathelicidin is unknown but human and various mammalian cathelicidins have shown efficacy against RV, including LL-37, protegrin-1, and SMAP-29. ${ }^{97}$ Exogenous administration has not been assessed in clinical trials yet but represents a possible therapeutic approach.

Vitamin D is commonly regarded for its effects on maintaining bone health and calcium homeostasis, but it also plays a role in supporting the innate immune system. Vitamin D is obtained through both diet and by the ultraviolet (UV) radiation conversion of 7-dehydrocholesterol to vitamin D3. Vitamin D becomes activated via the liver and the kidneys to form the active metabolite calcitriol, which mediates its effects through binding nuclear vitamin $\mathrm{D}$ receptors (VDR) within cells. There is also evidence that lung epithelium and various leukocytes can also convert vitamin $\mathrm{D}$ to its active form. ${ }^{98,99}$ Calcitriol binding leads to the upregulation of various HDPs, including LL37 (cathelicidin) in HBECs, ${ }^{100,101} \beta$-Defensin-2 (HBD2), and human cationic antimicrobial peptide (hCAP). ${ }^{102}$ Furthermore, single nucleotide variants in the VDR gene are associated with increased risk of URTI, again highlighting the importance of calcitriol in antiviral responses. ${ }^{103}$ In vitro work showed that HBECs infected with RV in the presence of vitamin D led to decreased viral replication and a rise in cathelicidin and IFN stimulated genes. $^{100}$

The exact dosing or treatment duration of vitamin $\mathrm{D}$ is less clear. A 2015 literature review concluded that vitamin $\mathrm{D}$ metabolites do not consistently reduce RV replication though they do lead to changes within type 1 IFNs and pro-inflammatory cytokines. ${ }^{102}$ A 2017 systematic review and meta-analysis covering 10,933 patients found an overall protective effect of vitamin D against URTI. ${ }^{104}$ A more recent meta-analysis in 2020 (currently in pre-print form), showed that daily administration of 400-1000 IU vitamin D conferred protection against URTI. ${ }^{76}$ Further data suggests that protective effects are maximal in individuals with pre-existing vitamin D deficiency (baseline 25hydroxyvitamin $\mathrm{D}$ concentration $<25 \mathrm{nmol} / \mathrm{L}){ }^{105}$ To our knowledge there have been no trials of vitamin D using the human viral challenge model.

\section{Modulation of the Host Response}

IFN responses, as previously discussed, are impaired in both asthma and COPD patients. Consequently, exogenous IFN has been explored as a broad-spectrum therapeutic approach against respiratory infection, of which the majority are due to rhinovirus. Numerous trials of intranasal IFN were conducted from the 1960s without success. The first randomised controlled trial using orally inhaled IFN- $\beta$ in 
patients with asthma was completed in $2014 .{ }^{67}$ The trial resulted in a significant improvement in lung function but the study did not meet its primary endpoint of clinical improvement, likely because most patients studied were mild, and asthma control in the placebo treated patients did not deteriorate significantly on virus infection. ${ }^{67} \mathrm{~A}$ further Phase II trial was terminated early due to an unanticipated low rate of asthma exacerbations but participants did record an improvement in morning peak expiratory flow (PEF) on taking IFN- $\beta .{ }^{106}$ More recent work has suggested that IFN- $\beta$ may be better administered prophylactically, and work remains ongoing. ${ }^{107}$ In November 2020, inhaled INF- $\beta$ was shown to be of clinical benefit in SARS-CoV-2 positive patients in a hospital-based Phase II clinical trial, suggesting further work against RV is warranted. ${ }^{108}$

Azithromycin is a macrolide antibiotic that has been shown to have immunomodulatory effects. In vitro work has shown HBECs pre-treated with azithromycin and then infected with RV-1B and RV-16 had significantly higher levels of RV induced IFNs and IFN stimulated genes. ${ }^{109}$ Further work has shown azithromycin induces IFN- $\beta$ and IFN- $\lambda$ though the exact mechanism remains unclear. ${ }^{110,111}$ A randomised control trial (AMAZES) found that longterm azithromycin prophylaxis reduced the number of asthma exacerbations that patients with symptomatic asthma experienced and also improved participants asthma-related quality of life. ${ }^{65}$ Despite this, the AZALEA randomised control trial of short-term azithromycin intervention versus placebo in acute exacerbations had no significant difference. ${ }^{66}$ Further work is needed to elucidate the mechanism of azithromycin induced IFN stimulation, for which the experimental infection model would be well suited.

Several positive stranded RNA viruses have been shown to manipulate the membranes of the host cell Golgi apparatus and the endoplasmic reticulum to create a viral replication complex. ${ }^{112} \mathrm{RV}$ appears to bind such membranes using the RV-3A gene region and various host proteins including phosphatidylinositol 4-kinase III beta $(\mathrm{PI} 4 \mathrm{~KB})^{113}$ and oxysterol binding protein (OSBP). ${ }^{114}$ PI4KB and OSBP are both substrates of protein kinase $\mathrm{D}$ (PKD) suggesting that targeting PKD may be another strategy. In vitro work has shown that inhibition of PKD reduced RV replication in a concentration dependent manner. ${ }^{15}$ PI4KB and OSBP targets are currently in development ${ }^{116}$ but have yet to undergo clinical trials.

Human N-myristoyltransferase (NMT) has emerged as another target. Host NMT myristoylates the VP0 region of the virus polyprotein, which is a key step in the formation of the viral capsid and subsequently creating a viable virion. IMP-1088 was developed as an inhibitor of human NMT1 and NMT2, and has shown promising results in vitro. ${ }^{117}$ It has yet to reach clinical trials.

\section{Neutralising Antibodies}

An alternative approach is to use antibodies that either bind the virion and cause aggregation; disrupt the virion structure; prevent virus entry/attachment; or preventing release of newly formed virions. Two neutralising and immunogenic sites have been identified on VP1 close to the canyon (NIm-1a and NIm-1b), and another two sites on VP2 and VP3 (NIm-2 and NIm-3 respectively) of the RV-2 and RV-14 serotypes. ${ }^{118,119}$ Unfortunately, these NIms are serotype specific which dramatically limits the possibility of a therapy effective against multiple serotypes. A solution may be to create a "cocktail" of multiple antibodies that provide protection across serotypes.

Antibodies may also be directed against host proteins, such as those critical for virus attachment and binding. Hayden et al demonstrated in 1988 that intranasally administered mouse monoclonal antibody specific for ICAM-1 reduced viral load and symptoms in human participants. ${ }^{120}$

\section{Soluble Proteins}

Tremacamra, a recombinant soluble ICAM-1 showed modest improvement in symptom score when given both pre and post RV infection. ${ }^{74}$ One drawback is the intense scheduling of doses, as 6 doses are given per day at 3 hour intervals intranasally. In more recent times, a mouse antihuman ICAM-1 antibody (14C11) has been developed which targets an epitope of ICAM-1 specific for viral entry. ${ }^{121}$ When given topically or systemically in mice, $14 \mathrm{C} 11$ reduced viral load, pro-inflammatory cytokines and blocked entry of RV-16 and RV-14. ${ }^{121}$ An approach to treat all forms of RV would be to create a cocktail of soluble ICAM-1, LDLR and CDHR3 though this remains to be studied and the dosing issue remains.

\section{Other Therapies}

\section{Budesonide}

Budesonide is a corticosteroid, most frequently used in the treatment of asthma and COPD via the inhaled route. When administered intranasally in mice, budesonide was shown to reduce RV viral load and also levels of proinflammatory IL-1 $\beta .^{122}$ 


\section{Gemcitabine}

Gemcitabine is a synthetic nucleoside deoxycytidine analogue in use as a chemotherapy agent, which has been demonstrated as efficacious in-vitro against RV-14, RV-21 and RV-71 in H1HeLa cells. Whilst its oncological use is associated with many unpleasant side effects which would surely preclude its use in the same fashion against RV, Kang et al have demonstrated limited cell toxicity and synergistic effects in combination with the guanine analogue ribavirin. ${ }^{123}$ Gemcitabine's action has been replicated in murine models via intranasal administration, and there is evidence that it acts via inhibition of CTP synthetase. ${ }^{124}$

\section{Quercetin}

Quercetin is a flavonoid found in plants and commonly eaten foods like broccoli and berries. A number of immunomodulatory effects have been attributed to the compound, including in vitro antiviral effects. Use in mouse models suggested that the compound reduced RV replication and cytokine responses. ${ }^{125}$ Further work in smoke exposed mouse COPD models suggests that inflammation associated with exacerbation after RV infection was reduced with dietary supplementation of quercetin. ${ }^{126}$

No clinical trials are yet forthcoming, although the groundwork for such a trial appears to be laid with a small safety trial assessing quercetin supplementation in patients with COPD reporting favorably in $2020 .{ }^{127}$

\section{Omalizumab (Anti-lgE)}

Recent work has shown that subjects with allergic asthma (as measured by high levels of total IgE) show an increase in their blood eosinophil count and declines in lung function following RV-16 viral challenge. ${ }^{52}$ The same study, by Heymann et al, found that asthma subjects pre-treated with omalizumab (an anti-IgE monoclonal antibody) for 8 weeks before and 3 weeks following virus inoculation showed earlier resolution of lung function, FeNO score, and symptom score. ${ }^{52}$

\section{Other Approaches}

Future efforts in drug discovery against RV infections may be directed by sophisticated computational means as described in Da Costa et al's 2017 paper describing the potential of compound (S)-7f against RV-14 using molecular and in silico models. ${ }^{128}$

Other novel targets have been identified through analysis of the lipidome of human bronchial epithelial cells, and commercially available enzyme inhibitors have been presented as potential inhibitors of RV infection and replication. ${ }^{129}$

Finally, advances at the nanoscale have allowed a better understanding of the interaction between chemical makeup, structure and mechanics of viruses, and inevitably opened a new door of possibilities for virus inhibition by "mechanical stiffening". ${ }^{130}$ Design, manufacture and evaluation of these compounds is awaited.

\section{Future Work}

Whilst an affordable and effective therapy against RVs continues to evade the scientific community, novel experimental therapies that have been uncovered in recent years offer new hope. It is likely that a variety of approaches will be required given the heterogeneity of human rhinoviruses. Antiviral therapies targeting the rhinovirus virion itself are among the oldest approaches but are yet to yield any significant breakthroughs. In vitro work on such therapies continues apace. The work on host defence peptides and in particular vitamin D looks promising and would be an obvious candidate for clinical trials using the rhinovirus challenge model, particularly given the abundance of data on its safety. Many other therapies remain in the experimental phase and should be watched closely.

With the emergence of the COVID-19 global pandemic, international attention has been thrust onto antiviral therapies and the need to produce a diverse array of strategies for this and future pandemics. We hope that with this newfound impetus and the hard work of many groups over the last 6 decades, that new progress will be uncovered. With multiple drug candidates awaiting clinical trials, we may be on the cusp of a new generation of antiviral therapies.

\section{Abbreviation}

14C11, anti-human ICAM-1 antibody; 3'UTR, 3-prime untranslated region; 5'UTR, 5-prime untranslated region; ACQ-6, asthma control questionnaire; AMAZES, effect of azithromycin on asthma exacerbations and quality of life in adults with persistent uncontrolled asthma (randomised controlled trial); AZALEA, Azithromycin for acute exacerbations of asthma (randomised clinical trial); COPD, chronic obstructive pulmonary disease; COVID-19, coronavirus disease (caused by SARS-CoV-2); CTP, cytidine triphosphate; FDA, Food and Drug Administration; GSNOR, S-nitroglutathione reductase; HBEC, human bronchial epithelial cells; HRV, (human) rhinovirus; IFN, interferon; ILC2s, type 2 innate lymphoid cells; LDL-R, low-density lipoprotein receptor; MDA-5, melanoma differentiation- 
associated protein 5; NMT, human N-myristoyltransferase; NO, nitric oxide; NOS, nitric oxide synthase; PCR, polymerase chain reaction; PI4KB, phosphatidylinositol 4-kinase III beta; RIG-I, retinoic acid-inducible gene I; RNA, ribonucleic acid; TLR, toll-like receptor; TSLP, thymic stromal lymphopoietin; URTI, upper respiratory tract infection; VDR, vitamin D receptors.

\section{Data Sharing Statement}

No additional data is held by the authors other than that which appears in the manuscript.

\section{Ethics Approval and Informed Consent}

Not required for this review.

\section{Acknowledgments}

No relevant acknowledgements.

\section{Author Contributions}

All authors made a significant contribution to the work reported, whether that is in the conception, study design, execution, acquisition of data, analysis and interpretation, or in all these areas; took part in drafting, revising or critically reviewing the article; gave final approval of the version to be published; have agreed on the journal to which the article has been submitted; and agree to be accountable for all aspects of the work.

\section{Funding}

Sebastian Johnston is a National Institute of Health Research (NIHR) Emeritus Senior Investigator, the Asthma UK Clinical Chair (Grant CH11SJ) and receives support from European Research Council Advanced Grant 788575, the NIHR Imperial Biomedical Research Centre (BRC) and Asthma UK Centre Grant AUK-BC-2015-01. The views expressed are those of the author(s) and not necessarily those of the NIHR or the Department of Health and Social Care.

\section{Disclosure}

James Coultas: no financial or non-financial competing interests to declare.

John Cafferkey: no financial or non-financial competing interests to declare.

Patrick Mallia: has received support from AstraZeneca to attend ERS congress.
Sebastian Johnston: reports personal fees from Virtus Respiratory Research, Myelo TherapeuticsĐmbH, Concert Pharmaceuticals, Bayer, Synairgen, Novartis, Boehringer Ingelheim, Chiesi, Gerson Lehrman Group, resTORbio, Bioforce, Materia Medical Holdings, PrepBio Pharma, Pulmotect, Virion Health, Lallemand Pharma and AstraZeneca, outside the submitted work; In addition, Professor Johnston has a patent: Wark PA, Johnston SL, Holgate ST, Davies DE, Antivirus Therapy for Respiratory diseases, UK patent application No. GB 0405 634.7, 12 March 2004, with royalties paid, a patent Wark PA, Johnston SL, Holgate ST, Davies DE, Interferon-Beta for Anti-Virus Therapy for Respiratory Diseases, International Patent Application No. PCT/GB05/50031, 12 March 2004, with royalties paid, and a patent Davies DE, Wark PA, Holgate ST, Johnston SL. Interferon Lambda Therapy for the Treatment of Respiratory disease. UK patent application No. 6779645.9, granted 15th August 2012, licensed.

\section{References}

1. Price WH. The isolation of a new virus associated with respiratory clinical disease in humans. Proc Natl Acad Sci USA. 1956;42 (12):892-896. doi:10.1073/pnas.42.12.892

2. Johnston SL, Pattemore PK, Sanderson G, et al. Community study of role of viral infections in exacerbations of asthma in 911 year old children. BMJ. 1995;310(6989):1225-1229. doi:10.1136/bmj.310.6989.1225

3. Seemungal T, Harper-Owen R, Bhowmik A, et al. Respiratory viruses, symptoms, and inflammatory markers in acute exacerbations and stable chronic obstructive pulmonary disease. Am J Respir Crit Care Med. 2001;164(9):1618-1623. doi:10.1164/ ajrccm.164.9.2105011

4. Aponte FE, Taboada B, Espinoza MA, et al. Rhinovirus is an important pathogen in upper and lower respiratory tract infections in Mexican children. Virol J. 2015;12:31. doi:10.1186/s12985-0150262-z

5. Redlberger-Fritz M, Kundi M, Aberle SW, Puchhammer-Stöckl E. Significant impact of nationwide SARS-CoV-2 lockdown measures on the circulation of other respiratory virus infections in Austria. J Clin Virol. 2021;137:104795. doi:10.1016/j.jcv.2021.104795

6. Weston S, Frieman MB. Respiratory Viruses. Reference Module in Biomedical Sciences. Elsevier; 2018.

7. Cafferkey J, Coultas JA, Mallia P. Human rhinovirus infection and COPD: role in exacerbations and potential for therapeutic targets. Expert Rev Respir Med. 2020;14(8):777-789. doi:10.1080/17476348.2020.1764354

8. Jacobs SE, Lamson DM, St George K, Walsh TJ. Human rhinoviruses. Clin Microbiol Rev. 2013;26(1):135-162.

9. McIntyre CL, Knowles NJ, Simmonds P. Proposals for the classification of human rhinovirus species A, B and C into genotypically assigned types. J Gen Virol. 2013;94(Pt 8):1791-1806. doi:10.1099/vir.0.053686-0

10. Lamson D, Renwick N, Kapoor V, et al. MassTag polymerasechain-reaction detection of respiratory pathogens, including a new rhinovirus genotype, that caused influenza-like illness in New York State during 2004-2005. J Infect Dis. 2006;194 (10):1398-1402. doi:10.1086/508551 
11. Lau SKP, Yip CCY, Woo PCY, Yuen KY. Human rhinovirus C: a newly discovered human rhinovirus species. Emerg Health Threats J. 2010;4(3):e2.

12. Palmenberg AC, Rathe JA, Liggett SB. Analysis of the complete genome sequences of human rhinovirus. J Allergy Clin Immunol. 2010;125(6):1190-1199. doi:10.1016/j.jaci.2010.04.010

13. Spickler C, Lippens J, Laberge M-K, et al. Phosphatidylinositol 4-kinase III beta is essential for replication of human rhinovirus and its inhibition causes a lethal phenotype in vivo. Antimicrob Agents Chemother. 2013;57(7):3358-3368. doi:10.1128/ AAC.00303-13

14. Ambros V, Baltimore D. Protein is linked to the 5' end of poliovirus RNA by a phosphodiester linkage to tyrosine. $J$ Biol Chem. 1978;253(15):5263-5266. doi:10.1016/S0021-9258(17) 30361-7

15. Sun D, Chen S, Cheng A, Wang M. Roles of the picornaviral 3C proteinase in the viral life cycle and host cells. Viruses. 2016;8 (3):82. doi:10.3390/v8030082

16. Appleby TC, Luecke H, Shim JH, et al. Crystal structure of complete rhinovirus RNA polymerase suggests front loading of protein primer. $J$ Virol. 2005;79(1):277-288. doi:10.1128/ JVI.79.1.277-288.2005

17. Colonno RJ, Condra JH, Mizutani S, Callahan PL, Davies ME, Murcko MA. Evidence for the direct involvement of the rhinovirus canyon in receptor binding. Proc Natl Acad Sci USA. 1988;85(15):5449-5453. doi:10.1073/pnas.85.15.5449

18. Bella J, Rossmann MG. ICAM-1 receptors and cold viruses. Pharm Acta Helv. 2000;74(2-3):291-297. doi:10.1016/S00316865(99)00056-4

19. Liu Y, Hill MG, Klose T, et al. Atomic structure of a rhinovirus C, a virus species linked to severe childhood asthma. Proc Natl Acad Sci USA. 2016;113(32):8997-9002. doi:10.1073/ pnas. 1606595113

20. Hofer F, Gruenberger M, Kowalski H, et al. Members of the low density lipoprotein receptor family mediate cell entry of a minor-group common cold virus. Proc Natl Acad Sci USA. 1994;91(5):1839-1842. doi:10.1073/pnas.91.5.1839

21. Bochkov YA, Palmenberg AC, Lee WM, et al. Molecular modeling, organ culture and reverse genetics for a newly identified human rhinovirus C. Nat Med. 2011;17(5):627-632. doi:10.1038/nm.2358

22. Everman JL, Sajuthi S, Saef B, et al. Functional genomics of CDHR3 confirms its role in HRV-C infection and childhood asthma exacerbations. $J$ Allergy Clin Immunol. 2019;144 (4):962-971. doi:10.1016/j.jaci.2019.01.052

23. Laza-Stanca V, Stanciu LA, Message SD, Edwards MR, Gern JE, Johnston SL. Rhinovirus replication in human macrophages induces NF-kappaB-dependent tumor necrosis factor alpha production. $J$ Virol. 2006;80(16):8248-8258. doi:10.1128/ JVI.00162-06

24. Slater L, Bartlett NW, Haas JJ, et al. Co-ordinated role of TLR3, RIG-I and MDA5 in the innate response to rhinovirus in bronchial epithelium. PLoS Pathog. 2010;6(11):e1001178. doi:10.1371/journal.ppat.1001178

25. Fensterl V, Chattopadhyay S, Sen GC. No love lost between viruses and interferons. Annu Rev Virol. 2015;2(1):549-572. doi:10.1146/annurev-virology-100114-055249

26. Kennedy JL, Turner RB, Braciale T, Heymann PW, Borish L. Pathogenesis of rhinovirus infection. Curr Opin Virol. 2012;2 (3):287-293. doi:10.1016/j.coviro.2012.03.008

27. Kaul P, Biagioli MC, Singh I, Turner RB. Rhinovirus-induced oxidative stress and interleukin-8 elaboration involves p47-phox but is independent of attachment to intercellular adhesion molecule-1 and viral replication. $J$ Infect Dis. 2000;181 (6):1885-1890. doi:10.1086/315504
28. Mallia P, Message SD, Kebadze T, Parker HL, Kon OM, Johnston SL. An experimental model of rhinovirus induced chronic obstructive pulmonary disease exacerbations: a pilot study. Respir Res. 2006;7(1):116. doi:10.1186/1465-9921-7-116

29. Mallia P, Message SD, Gielen V, et al. Experimental rhinovirus infection as a human model of chronic obstructive pulmonary disease exacerbation. Am J Respir Crit Care Med. 2011;183 (6):734-742. doi:10.1164/rccm.201006-0833OC

30. Footitt J, Mallia P, Durham AL, et al. Oxidative and nitrosative stress and histone deacetylase-2 activity in exacerbations of COPD. Chest. 2016;149(1):62-73. doi:10.1378/chest.14-2637

31. Hilzendeger C, da Silva J, Henket M, et al. Reduced sputum expression of interferon-stimulated genes in severe COPD. Int $J$ Chron Obstruct Pulmon Dis. 2016; Volume 11 (11):1485-1494. doi:10.2147/COPD.S105948

32. García-Valero J, Olloquequi J, Montes JF, et al. Deficient pulmonary IFN- $\beta$ expression in COPD patients. PLoS One. 2019;14 (6):e0217803. doi:10.1371/journal.pone.0217803

33. Baines KJ, Hsu ACY, Tooze M, Gunawardhana LP, Gibson PG, Wark PAB. Novel immune genes associated with excessive inflammatory and antiviral responses to rhinovirus in COPD. Respir Res. 2013;14:15. doi:10.1186/1465-9921-14-15

34. Singanayagam A, Loo SL, Calderazzo M, et al. Antiviral immunity is impaired in COPD patients with frequent exacerbations. Am J Physiol Lung Cell Mol Physiol. 2019;317(6):L893-L903. doi:10.1152/ajplung.00253.2019

35. Wark PAB, Johnston SL, Bucchieri F, et al. Asthmatic bronchial epithelial cells have a deficient innate immune response to infection with rhinovirus. $J$ Exp Med. 2005;201(6):937-947. doi:10.1084/jem.20041901

36. Contoli M, Message SD, Laza-Stanca V, et al. Role of deficient type III interferon-lambda production in asthma exacerbations. Nat Med. 2006;12(9):1023-1026. doi:10.1038/nm1462

37. Edwards MR, Regamey N, Vareille M, et al. Impaired innate interferon induction in severe therapy resistant atopic asthmatic children. Mucosal Immunol. 2013;6(4):797-806. doi:10.1038/ mi.2012.118

38. Miller EK, Hernandez JZ, Wimmenauer V, et al. A mechanistic role for type III IFN- $\lambda 1$ in asthma exacerbations mediated by human rhinoviruses. Am J Respir Crit Care Med. 2012;185 (5):508-516. doi:10.1164/rccm.201108-1462OC

39. Hansel TT, Tunstall T, Trujillo-Torralbo M-B, et al. A comprehensive evaluation of nasal and bronchial cytokines and chemokines following experimental rhinovirus infection in allergic asthma: increased interferons (IFN- $\gamma$ and IFN- $\lambda$ ) and type 2 inflammation (IL-5 and IL-13). EBioMedicine. 2017;19:128-138. doi:10.1016/j.ebiom.2017.03.033

40. Kennedy JL, Shaker M, McMeen V, et al. Comparison of viral load in individuals with and without asthma during infections with rhinovirus. Am J Respir Crit Care Med. 2014;189 (5):532-539. doi:10.1164/rccm.201310-1767OC

41. Farne HA, Johnston SL. Immune mechanisms of respiratory viral infections in asthma. Curr Opin Immunol. 2017;48:31-37. doi:10.1016/j.coi.2017.07.017

42. Jackson DJ, Makrinioti H, Rana BMJ, et al. IL-33-dependent type 2 inflammation during rhinovirus-induced asthma exacerbations in vivo. Am J Respir Crit Care Med. 2014;190(12):1373-1382. doi:10.1164/rccm.201406-1039OC

43. Tyrrell DA. A view from the common cold unit. Antiviral Res. 1992;18(2):105-125. doi:10.1016/0166-3542(92)90032-Z

44. Andrewes CH. The common cold. Br Med Bull. 1953;9 (3):206-207. doi:10.1093/oxfordjournals.bmb.a074357

45. Rosenbaum JR, Sepkowitz KA. Infectious disease experimentation involving human volunteers. Clin Infect Dis. 2002;34 (7):963-971. doi:10.1086/339328 
46. Sperber SJ, Hunger SB, Schwartz B, Pestka S. Anti-rhinoviral activity of recombinant and hybrid species of interferon alpha. Antiviral Res. 1993;22(2-3):121-129. doi:10.1016/01663542(93)90090-6

47. Al-Nakib W, Higgins PG, Barrow I, Tyrrell DA, Lenox-Smith I, Ishitsuka H. Intranasal chalcone, Ro 09-0410, as prophylaxis against rhinovirus infection in human volunteers. $J$ Antimicrob Chemother. 1987;20(6):887-892. doi:10.1093/jac/20.6.887

48. al-Nakib W, Higgins PG, Barrow GI, et al. Suppression of colds in human volunteers challenged with rhinovirus by a new synthetic drug (R61837). Antimicrob Agents Chemother. 1989;33 (4):522-525. doi:10.1128/AAC.33.4.522

49. Lemanske RF, Dick EC, Swenson CA, Vrtis RF, Busse WW. Rhinovirus upper respiratory infection increases airway hyperreactivity and late asthmatic reactions. J Clin Invest. 1989;83 (1):1-10. doi:10.1172/JCI113843

50. Bardin PG, Fraenkel DJ, Sanderson G, et al. Amplified rhinovirus colds in atopic subjects. Clin Exp Allergy. 1994;24(5):457-464. doi:10.1111/j.1365-2222.1994.tb00934.x

51. de Gouw HW, Grünberg K, Schot R, Kroes AC, Dick EC, Sterk PJ. Relationship between exhaled nitric oxide and airway hyperresponsiveness following experimental rhinovirus infection in asthmatic subjects. Eur Respir J. 1998;11(1):126-132. doi:10.1183/09031936.98.11010126

52. Heymann PW, Tae PM, Woodfolk JA, et al. Understanding the asthmatic response to an experimental rhinovirus infection: exploring the effects of blocking IgE. J Allergy Clin Immunol. 2020;146(3):545-554. doi:10.1016/j.jaci.2020.01.035

53. Zambrano JC, Carper HT, Rakes GP, et al. Experimental rhinovirus challenges in adults with mild asthma: response to infection in relation to IgE. $J$ Allergy Clin Immunol. 2003;111 (5):1008-1016. doi:10.1067/mai.2003.1396

54. Togo Y, Schwartz AR, Hornick RB. Antiviral effect of 3, 4-dihydro-1-isoquinolineacetamide hydrochloride in experimental human rhinovirus infection. Antimicrob Agents Chemother. 1973;4(6):612-616. doi:10.1128/AAC.4.6.612

55. Turner RB, Riker DK, Gangemi JD. Ineffectiveness of echinacea for prevention of experimental rhinovirus colds. Antimicrob Agents Chemother. 2000;44(6):1708-1709. doi:10.1128/ AAC.44.6.1708-1709.2000

56. Gaffey MJ, Gwaltney JM, Sastre A, Dressler WE, Sorrentino JV, Hayden FG. Intranasally and orally administered antihistamine treatment of experimental rhinovirus colds. Am Rev Respir Dis. 1987;136(3):556-560. doi:10.1164/ajrccm/136.3.556

57. Winther B, Buchert D, Turner RB, Hendley JO, Tschaikin M. Decreased rhinovirus shedding after intranasal oxymetazoline application in adults with induced colds compared with intranasal saline. Am J Rhinol Allergy. 2010;24(5):374-377. doi:10.2500/ ajra.2010.24.3491

58. Togo Y, Durr FE, Laurenzana DA. Clinical evaluation of prophylactic intranasal 1-phenyl-3-(4-phenyl-2-thiazolyl) guanidine (CL $88,277)$ medication against rhinovirus 44 challenge. Med Microbiol Immunol. 1977;163(1):37-44. doi:10.1007/ BF02126707

59. Sperber SJ, Sorrentino JV, Riker DK, Hayden FG. Evaluation of an alpha agonist alone and in combination with a nonsteroidal antiinflammatory agent in the treatment of experimental rhinovirus colds. Bull N Y Acad Med. 1989;65(1):145-160.

60. Higgins PG, al-Nakib W, Barrow GI, Tyrrell DA. Recombinant human interferon-gamma as prophylaxis against rhinovirus colds in volunteers. J Interferon Res. 1988;8(5):591-596. doi:10.1089/ jir.1988.8.591

61. Al-Nakib W, Higgins PG, Barrow I, Batstone G, Tyrrell DA. Prophylaxis and treatment of rhinovirus colds with zinc gluconate lozenges. $J$ Antimicrob Chemother. 1987;20(6):893-901. doi:10.1093/jac/20.6.893
62. The Academy of Medical Sciences. Controlled human infection model studies: summary of a workshop held on 6 February 2018. The Academy of Medical Sciences [Internet]. 2018 [cited December 15, 2020]; Available from: https://acmedsci.ac.uk/filedownload/55062331. Accessed June 4, 2021.

63. Johnston SL. Experimental models of rhinovirus-induced exacerbations of asthma. Am J Respir Crit Care Med. 2003;168 (10):1145-1146. doi:10.1164/rccm.2309004

64. Girkin J, Maltby S, Singanayagam A, Bartlett N, Mallia P. In vivo experimental models of infection and disease. In: Rhinovirus Infections. Elsevier; 2019:195-238.

65. Gibson PG, Yang IA, Upham JW, et al. Effect of azithromycin on asthma exacerbations and quality of life in adults with persistent uncontrolled asthma (AMAZES): a randomised, double-blind, placebo-controlled trial. Lancet. 2017;390(10095):659-668. doi:10.1016/S0140-6736(17)31281-3

66. Johnston SL, Szigeti M, Cross M, et al. Azithromycin for acute exacerbations of asthma: the AZALEA randomized clinical trial. JAMA Intern Med. 2016;176(11):1630-1637. doi:10.1001/ jamainternmed.2016.5664

67. Djukanović R, Harrison T, Johnston SL, et al. The effect of inhaled IFN- $\beta$ on worsening of asthma symptoms caused by viral infections. A randomized trial. Am J Respir Crit Care Med. 2014;190(2):145-154. doi:10.1164/rccm.201312-2235OC

68. Hayden FG, Andries K, Janssen PA. Safety and efficacy of intranasal pirodavir (R77975) in experimental rhinovirus infection. Antimicrob Agents Chemother. 1992;36(4):727-732. doi:10.1128/AAC.36.4.727

69. Hayden FG, Hipskind GJ, Woerner DH, et al. Intranasal pirodavir (R77,975) treatment of rhinovirus colds. Antimicrob Agents Chemother. 1995;39(2):290-294. doi:10.1128/AAC.39.2.290

70. Hayden FG, Herrington DT, Coats TL, et al. Efficacy and safety of oral pleconaril for treatment of colds due to picornaviruses in adults: results of 2 double-blind, randomized, placebo-controlled trials. Clin Infect Dis. 2003;36(12):1523-1532. doi:10.1086/ 375069

71. Smee DF, Evans WJ, Nicolaou KC, Tarbet EB, Day CW Susceptibilities of enterovirus D68, enterovirus 71, and rhinovirus 87 strains to various antiviral compounds. Antiviral Res. 2016;131:61-65. doi:10.1016/j.antiviral.2016.04.003

72. Andersen DO, Murray BK, Robins RK, North JA. In vitro antiviral activity of ribavirin against picornaviruses. Antivir Chem Chemother. 1992;3(6):361-370. doi:10.1177/ 095632029200300606

73. Ruuskanen O, Waris M, Kainulainen L. Treatment of persistent rhinovirus infection with pegylated interferon $\alpha 2 \mathrm{a}$ and ribavirin in patients with hypogammaglobulinemia. Clin Infect Dis. 2014;58 (12):1784-1786. doi:10.1093/cid/ciu169

74. Turner RB, Wecker MT, Pohl G, et al. Efficacy of tremacamra, a soluble intercellular adhesion molecule 1 , for experimental rhinovirus infection: a randomized clinical trial. JAMA. 1999;281(19):1797-1804. doi:10.1001/jama.281.19.1797

75. Vapendavir significantly improves upper respiratory symptoms of naturally acquired rhinovirus infection in asthmatic adults: results of a Phase 2 clinical trial | European Respiratory Society [Internet]. [cited May 15, 2021]. Available from: https://erj.ers journals.com/content/42/Suppl_57/1493. Accessed June 4, 2021.

76. Jolliffe DA, Camargo CA, Sluyter JD, et al. Vitamin D supplementation to prevent acute respiratory infections: a systematic review and meta-analysis of aggregate data from randomised controlled trials. Lancet Diabetes Endocrinol. 2021;9(5):276-292. doi:10.1016/S2213-8587(21)00051-6

77. Beaucourt S, Vignuzzi M. Ribavirin: a drug active against many viruses with multiple effects on virus replication and propagation. Molecular basis of ribavirin resistance. Curr Opin Virol. 2014;8:10-15. doi:10.1016/j.coviro.2014.04.011 
78. Ledford RM, Patel NR, Demenczuk TM, et al. VP1 sequencing of all human rhinovirus serotypes: insights into genus phylogeny and susceptibility to antiviral capsid-binding compounds. $J$ Virol. 2004;78(7):3663-3674. doi:10.1128/JVI.78.7.36633674.2004

79. Basta HA, Ashraf S, Sgro JY, Bochkov YA, Gern JE, Palmenberg AC. Modeling of the human rhinovirus C capsid suggests possible causes for antiviral drug resistance. Virology. 2014;448:82-90. doi:10.1016/j.virol.2013.10.004

80. Schwitzer G. How the media left the evidence out in the cold. $B M J$. 2003;326(7403):1403-1404. doi:10.1136/bmj.326.7403.1403

81. ClinicalTrials.gov. Effects of pleconaril nasal spray on common cold symptoms and asthma exacerbations following rhinovirus exposure (study P04295). ClinicalTrials.gov: ClinicalTrials.gov; 2015.

82. Andries K, Dewindt B, Snoeks J, et al. In vitro activity of pirodavir (R 77975), a substituted phenoxy-pyridazinamine with broad-spectrum antipicornaviral activity. Antimicrob Agents Chemother. 1992;36(1):100-107. doi:10.1128/AAC.36.1.100

83. Biota Pharmaceuticals. A phase 2 study of vapendavir in asthmatic adults with symptomatic human rhinovirus infection (SPIRITUS) [Internet]. ClinicalTrials.gov, editor. ClinicalTrials. gov: ClinicalTrials.gov; 2018 [cited February 28, 2021]. Available from: https://clinicaltrials.gov/ct2/show/ NCT02367313. Accessed June 4, 2021.

84. Wald J, Pasin M, Richter M, et al. Cryo-EM structure of pleconaril-resistant rhinovirus-B5 complexed to the antiviral OBR-5-340 reveals unexpected binding site. Proc Natl Acad Sci USA. 2019;116(38):19109-19115. doi:10.1073/pnas.1904732116

85. Makarov VA, Braun H, Richter M, et al. Pyrazolopyrimidines: potent inhibitors targeting the capsid of rhino- and enteroviruses. Chem Med Chem. 2015;10(10):1629-1634. doi:10.1002/ cmdc.201500304

86. Lacroix C, Laconi S, Angius F, et al. In vitro characterisation of a pleconaril/pirodavir-like compound with potent activity against rhinoviruses. Virol J. 2015;12:106. doi:10.1186/s12985-0150330-4

87. Dragovich PS, Prins TJ, Zhou R, et al. Structure-based design, synthesis, and biological evaluation of irreversible human rhinovirus $3 \mathrm{C}$ protease inhibitors. 4 . Incorporation of P1 lactam moieties as L-glutamine replacements. J Med Chem. 1999;42 (7):1213-1224. doi:10.1021/jm9805384

88. Patick AK, Binford SL, Brothers MA, et al. In vitro antiviral activity of AG7088, a potent inhibitor of human rhinovirus $3 \mathrm{C}$ protease. Antimicrob Agents Chemother. 1999;43(10):2444-2450. doi:10.1128/AAC.43.10.2444

89. Kaiser L, Crump CE, Hayden FG. In vitro activity of pleconaril and AG7088 against selected serotypes and clinical isolates of human rhinoviruses. Antiviral Res. 2000;47(3):215-220. doi:10.1016/S0166-3542(00)00106-6

90. Zalman LS, Brothers MA, Dragovich PS, et al. Inhibition of human rhinovirus-induced cytokine production by AG7088, a human rhinovirus $3 \mathrm{C}$ protease inhibitor. Antimicrob Agents Chemother. 2000;44(5):1236-1241. doi:10.1128/AAC.44.5.12361241.2000

91. Hsyu PH, Yk P, Gersten M, Penning CA, Kerr BM. Pharmacokinetics and safety of an antirhinoviral agent, ruprintrivir, in healthy volunteers. Antimicrob Agents Chemother. 2002;46 (2):392-397.

92. Hayden FG, Turner RB, Gwaltney JM, et al. Phase II, randomized, double-blind, placebo-controlled studies of ruprintrivir nasal spray 2-percent suspension for prevention and treatment of experimentally induced rhinovirus colds in healthy volunteers. Antimicrob Agents Chemother. 2003;47(12):3907-3916. doi:10.1128/AAC.47.12.3907-3916.2003
93. Kawatkar SP, Gagnon M, Hoesch V, et al. Design and structure-activity relationships of novel inhibitors of human rhinovirus 3C protease. Bioorg Med Chem Lett. 2016;26 (14):3248-3252. doi:10.1016/j.bmcl.2016.05.066

94. Sanders SP, Siekierski ES, Porter JD, Richards SM, Proud D. Nitric oxide inhibits rhinovirus-induced cytokine production and viral replication in a human respiratory epithelial cell line. $J$ Virol. 1998;72(2):934-942. doi:10.1128/JVI.72.2.934-942.1998

95. Yang Z, Bochkov YA, Voelker DR, Foster MW, Que LG. Identification of a novel inhibitor of human rhinovirus replication and inflammation in airway epithelial cells. Am J Respir Cell Mol Biol. 2019;60(1):58-67. doi:10.1165/rcmb.2018-00580C

96. Shim A, Song JH, Kwon BE, et al. Therapeutic and prophylactic activity of itraconazole against human rhinovirus infection in a murine model. Sci Rep. 2016;6:23110. doi:10.1038/srep23110

97. Sousa FH, Casanova V, Findlay F, et al. Cathelicidins display conserved direct antiviral activity towards rhinovirus. Peptides. 2017;95:76-83. doi:10.1016/j.peptides.2017.07.013

98. Hansdottir S, Monick MM, Hinde SL, Lovan N, Look DC, Hunninghake GW. Respiratory epithelial cells convert inactive vita$\mathrm{min} \mathrm{D}$ to its active form: potential effects on host defense. J Immunol. 2008;181(10):7090-7099. doi:10.4049/jimmunol.181.10.7090

99. Liu PT, Stenger S, Li H, et al. Toll-like receptor triggering of a vitamin D-mediated human antimicrobial response. Science. 2006;311(5768):1770-1773. doi:10.1126/science.1123933

100. Telcian AG, Zdrenghea MT, Edwards MR, et al. Vitamin D increases the antiviral activity of bronchial epithelial cells in vitro. Antiviral Res. 2017;137:93-101. doi:10.1016/j.antiviral.2016.11.004

101. Schögler A, Muster RJ, Kieninger E, et al. Vitamin D represses rhinovirus replication in cystic fibrosis cells by inducing LL-37. Eur Respir J. 2016;47(2):520-530. doi:10.1183/13993003.006652015

102. Greiller CL, Martineau AR. Modulation of the immune response to respiratory viruses by vitamin D. Nutrients. 2015;7 (6):4240-4270. doi:10.3390/nu7064240

103. Jolliffe DA, Greiller CL, Mein CA, et al. Vitamin D receptor genotype influences risk of upper respiratory infection. $\mathrm{Br} J$ Nutr. 2018;120(8):891-900. doi:10.1017/S000711451800209X

104. Martineau AR, Jolliffe DA, Hooper RL, et al. Vitamin D supplementation to prevent acute respiratory tract infections: systematic review and meta-analysis of individual participant data. $B M J$. 2017;356:i6583. doi:10.1136/bmj.i6583

105. Martineau AR, Jolliffe DA, Greenberg L, et al. Vitamin D supplementation to prevent acute respiratory infections: individual participant data meta-analysis. Health Technol Assess. 2019;23(2):1-44. doi:10.3310/hta23020

106. McCrae C, Olsson M, Gustafson P, et al. INEXAS: a phase 2 randomized trial of on-demand inhaled interferon beta-1a in severe asthmatics. Clin Exp Allergy. 2021;51(2):273-283. doi:10.1111/cea.13765

107. Watson A, Spalluto CM, McCrae C, et al. Dynamics of IFN- $\beta$ responses during respiratory viral infection. Insights for therapeutic strategies. Am J Respir Crit Care Med. 2020;201(1):83-94. doi:10.1164/rccm.201901-0214OC

108. Monk PD, Marsden RJ, Tear VJ, et al. Safety and efficacy of inhaled nebulised interferon beta-1a (SNG001) for treatment of SARS-CoV-2 infection: a randomised, double-blind, placebo-controlled, phase 2 trial. Lancet Respir Med. 2021;9 (2):196-206. doi:10.1016/S2213-2600(20)30511-7

109. Gielen V, Johnston SL, Edwards MR. Azithromycin induces anti-viral responses in bronchial epithelial cells. Eur Respir J. 2010;36(3):646-654. doi:10.1183/09031936.00095809

110. Porter JD, Watson J, Roberts LR, et al. Identification of novel macrolides with antibacterial, anti-inflammatory and type I and III IFN-augmenting activity in airway epithelium. $J$ Antimicrob Chemother. 2016;71(10):2767-2781. doi:10.1093/jac/dkw222 
111. Menzel M, Akbarshahi H, Bjermer L, Uller L. Azithromycin induces anti-viral effects in cultured bronchial epithelial cells from COPD patients. Sci Rep. 2016;28(6):28698. doi:10.1038/ srep28698

112. Mejdrová I, Chalupská D, Plačková P, et al. Rational design of novel highly potent and selective phosphatidylinositol 4-kinase III $\beta$ (PI4KB) inhibitors as broad-spectrum antiviral agents and tools for chemical biology. J Med Chem. 2017;60(1):100-118. doi:10.1021/acs.jmedchem.6b01465

113. Greninger AL, Knudsen GM, Betegon M, Burlingame AL, Derisi JL. The 3A protein from multiple picornaviruses utilizes the golgi adaptor protein ACBD3 to recruit PI4KIII $\beta$. $J$ Virol. 2012;86(7):3605-3616. doi:10.1128/JVI.06778-11

114. Arita M, Kojima H, Nagano T, Okabe T, Wakita T, Shimizu H. Oxysterol-binding protein family $\mathrm{I}$ is the target of minor enviroxime-like compounds. J Virol. 2013;87(8):4252-4260. doi:10.1128/JVI.03546-12

115. Guedán A, Swieboda D, Charles M, et al. Investigation of the role of protein kinase $\mathrm{D}$ in human rhinovirus replication. $J$ Virol. 2017;91(9). doi:10.1128/JVI.00217-17

116. Tóth B, Balla A, Ma H, Knight ZA, Shokat KM, Balla T. Phosphatidylinositol 4-kinase IIIbeta regulates the transport of ceramide between the endoplasmic reticulum and Golgi. $J$ Biol Chem. 2006;281(47):36369-36377. doi:10.1074/jbc.M604935200

117. Mousnier A, Bell AS, Swieboda DP, et al. Fragment-derived inhibitors of human N-myristoyltransferase block capsid assembly and replication of the common cold virus. Nat Chem. 2018;10 (6):599-606. doi:10.1038/s41557-018-0039-2

118. Carey BS, Barclay WS, Russell SM, Tyrrell DA. The specificity of antibodies induced by infection with rhinovirus type 2. J Med Virol. 1992;36(4):251-258. doi:10.1002/jmv.1890360404

119. Hastings GZ, Speller SA, Francis MJ. Neutralizing antibodies to human rhinovirus produced in laboratory animals and humans that recognize a linear sequence from VP2. J Gen Virol. 1990;71(Pt 12)):3055-3059. doi:10.1099/0022-1317-71-12-3055

120. Hayden FG, Gwaltney JM, Colonno RJ. Modification of experimental rhinovirus colds by receptor blockade. Antiviral Res. 1988;9(4):233-247. doi:10.1016/0166-3542(88)90055-1
121. Traub S, Nikonova A, Carruthers A, et al. An anti-human ICAM-1 antibody inhibits rhinovirus-induced exacerbations of lung inflammation. PLoS Pathog. 2013;9(8):e1003520. doi:10.1371/journal.ppat.1003520

122. Kim S-R, Song J-H, Ahn J-H, et al. Antiviral and anti-inflammatory activity of budesonide against human rhinovirus infection mediated via autophagy activation. Antiviral Res. 2018;151:87-96. doi:10.1016/j.antiviral.2018.01.012

123. Kang H, Kim C, Kim D, et al. Synergistic antiviral activity of gemcitabine and ribavirin against enteroviruses. Antiviral Res. 2015;124:1-10. doi:10.1016/j.antiviral.2015.10.011

124. Song JH, Kim SR, Heo EY, et al. Antiviral activity of gemcitabine against human rhinovirus in vitro and in vivo. Antiviral Res. 2017;145:6-13. doi:10.1016/j.antiviral.2017.07.003

125. Ganesan S, Faris AN, Comstock AT, et al. Quercetin inhibits rhinovirus replication in vitro and in vivo. Antiviral Res. 2012;94(3):258-271. doi:10.1016/j.antiviral.2012.03.005

126. Farazuddin M, Mishra R, Jing Y, Srivastava V, Comstock AT, Sajjan US. Quercetin prevents rhinovirus-induced progression of lung disease in mice with COPD phenotype. PLoS One. 2018;13 (7):e0199612. doi:10.1371/journal.pone.0199612

127. Han MK, Barreto TA, Martinez FJ, Comstock AT, Sajjan US. Randomised clinical trial to determine the safety of quercetin supplementation in patients with chronic obstructive pulmonary disease. BMJ Open Respir Res. 2020;7(1):e000392. doi:10.1136/ bmjresp-2018-000392

128. Da Costa L, Scheers E, Coluccia A, et al. Heterocyclic pharmacochemistry of new rhinovirus antiviral agents: a combined computational and experimental study. Eur $J$ Med Chem. 2017;140:528-541. doi:10.1016/j.ejmech.2017.09.036

129. Nguyen A, Guedán A, Mousnier A, et al. Host lipidome analysis during rhinovirus replication in HBECs identifies potential therapeutic targets. J Lipid Res. 2018;59(9):1671-1684. doi:10.1194/ jlr.M085910

130. Valbuena A, Rodríguez-Huete A, Mateu MG. Mechanical stiffening of human rhinovirus by cavity-filling antiviral drugs. Nanoscale. 2018;10(3):1440-1452. doi:10.1039/C7NR08704G

\section{Publish your work in this journal}

The Journal of Experimental Pharmacology is an international, peerreviewed, open access journal publishing original research, reports, reviews and commentaries on all areas of laboratory and experimental pharmacology. The manuscript management system is completely

Submit your manuscript here: https://www.dovepress.com/journal-of-experimental-pharmacology-journal online and includes a very quick and fair peer-review system. Visit http://www.dovepress.com/testimonials.php to read real quotes from published authors. 